\title{
Erratum to: Autosomal recessive lissencephaly with cerebellar hypoplasia is associated with a loss-of-function mutation in $C D K 5$
}

\author{
Daniella Magen - Ayala Ofir · Liron Berger · Dorit Goldsher · Ayelet Eran · \\ Nasser Katib · Yousif Nijem • Euvgeni Vlodavsky · Shay Tzur · Doron M. Behar • \\ Yakov Fellig $\cdot$ Hanna Mandel
}

Published online: 22 January 2015

(C) Springer-Verlag Berlin Heidelberg 2015

\section{Erratum to: Hum Genet}

DOI 10.1007/s00439-014-1522-5

Sixth author 'Nasser Katib' and ninth author 'Shay Tzur' names are published with typo errors in the official publication. The correct names are Nasser Katib and Shay Tzur. The complete author group is given below.

Daniella Magen · Ayala Ofir · Liron Berger · Dorit Goldsher · Ayelet Eran · Nasser Katib - Yousif Nijem · Euvgeni Vlodavsky · Shay Tzur · Doron M. Behar · Yakov Fellig · Hanna Mandel

The online version of the original article can be found under doi:10.1007/s00439-014-1522-5.

D. Magen $(\varangle)$

Pediatric Nephrology Institute, Rambam Health Care Campus, Haifa, Israel

e-mail: danmag@tx.technion.ac.il

D. Magen $\cdot$ A. Ofir $\cdot$ L. Berger $\cdot$ S. Tzur $\cdot$ D. M. Behar Laboratory of Molecular Medicine, The Rappaport Faculty of Medicine and Research Institute, Technion-Israel Institute of Technology, Haifa, Israel

D. Goldsher · A. Eran

Department of Diagnostic Imaging, Rambam Health Care

Campus, Haifa, Israel

D. Goldsher · A. Eran · E. Vlodavsky · H. Mandel

The Rappaport Faculty of Medicine, Technion-Israel Institute of Technology, Haifa, Israel

N. Katib

Department of Family Medicine, Clalit Health Services, Ozer, Lower Galilee, Israel
Y. Nijem

Pediatric and Neonatal Unit, Nazareth Hospital EMMS,

Nazareth, Israel

E. Vlodavsky

Department of Pathology, Rambam Health Care Campus, Haifa, Israel

Y. Fellig

Department of Pathology, Hadassah Hebrew University Medical

Center, Jerusalem, Israel

H. Mandel

Metabolic Unit, Rambam Health Care Campus, Haifa, Israel 